Article

\title{
Why Social Exclusion Persists among Older People in Australia
}

\author{
Riyana Miranti ${ }^{1, *}$ and Peng $\mathrm{Yu}^{2}$ \\ ${ }^{1}$ National Centre for Social and Economic Modelling, Institute for Governance and Policy Analysis, University of \\ Canberra, Canberra, 2601, Australia; E-Mail: riyana.miranti@canberra.edu.au \\ ${ }^{2}$ Australian Government Department of Social Services, Canberra, 2900, Australia; E-Mail: peng.yu@dss.gov.au \\ * Corresponding author
}

Submitted: 14 December 2014 | In Revised Form: 22 May 2015 | Accepted: 22 May 2015 |

Published: 24 July 2015

\begin{abstract}
The existing literature on social exclusion among older people, though relatively limited, suggests that disadvantage among older people is cumulative in nature. Some aspects of disadvantage starting at early life stages have long-term consequences. As such, older people with disadvantages may be subject to higher risks of persistent social exclusion. This article aims to improve understanding of social exclusion and its persistence among senior Australians in three ways. Firstly, the incidence of social exclusion among older people is analysed using selected indicators. Secondly, the study examines whether an older person experiencing social exclusion at one time is more likely to experience it again (persistence). Thirdly, it investigates what factors may be protecting older people from social exclusion. The analysis is conducted using the first eight waves of the Household, Income and Labour Dynamics in Australia (HILDA) Survey. The sample of older people is disaggregated into a younger group (55-64 years at wave 1) and an older group (65+ years). The article suggests that higher education and income, as well as better health conditions and previous employment experiences, are important protective factors from social exclusion for older Australians.
\end{abstract}

\section{Keywords}

Australia; disadvantage; elderly; social exclusion; persistence; older people; senior

Issue

This article is part of the special issue "Indicators and Measurement of Social Inclusion", edited by Professor Peter Huxley (Bangor University, UK).

(C) 2015 by the authors; licensee Cogitatio (Lisbon, Portugal). This article is licensed under a Creative Commons Attribution 4.0 International License (CC BY).

\section{Introduction}

Social exclusion has emerged as a key feature in the analysis of disadvantage in developed countries. While it was introduced for the first time by Frenchman Rene Lenoir (1974), this concept spreads throughout Europe in the 1980s and was increasingly incorporated formally into country policy frameworks (Hayes, Gray, \& Edwards, 2008). Social exclusion is commonly defined as “...a complex and multi-dimensional process. It involves the lack or denial of resources, rights, goods and services and the inability to participate in the normal relationships and activities available to the majority of people in a society, whether in economic, social, cul- tural, or political arenas. It affects both the quality of life of individuals and the equity and cohesion of society as a whole" (Levitas et al., 2007, p. 86).

Age, as argued by the United Nations (2007), is one factor that is related to social exclusion. Nevertheless, the discussion surrounding social exclusion often focuses on working-age adults, and older people are rarely examined. ${ }^{1}$

One exception is the work undertaken by the UK

\footnotetext{
${ }^{1}$ Australian researchers have also examined social exclusion for children in a cross sectional and regional setting (see for example McNamara, Tanton, Daly, \& Harding, 2009, and Tanton, Harding, Daly, McNamara, \& Yap, 2010).
} 
Social Inclusion Unit (see Phillipson \& Scharf, 2004, and UK Social Exclusion Unit Office of the Deputy Prime Minister, 2006). They have developed a conceptual framework specifically for older people, and three key reasons are highlighted (Lui, Warburton, Winterton, \& Bartlett, 2011, p. 269): first, accumulative disadvantage (that is, experiencing exclusion in mid-life leads to further exclusion at an older age); second, key life events or transitions happening later in life like the death of a partner; third, age discrimination that may marginalise older people.

In Australia social exclusion of older people is a particularly pressing issue. Like many other developed countries, Australia has an ageing population. The government is under increasing pressure in terms of providing outlays for age and service pensions, and spending for health care and age services (Commonwealth of Australia, 2010). There is also a growing concern about older people losing independence or autonomy in many aspects of life (Kneale, 2012). However, so far there has been little research into social exclusion of older people in Australia (Naughtin, 2008).

A few Australian studies find increasing economic and social inequalities among older people (Faulkner, 2007; Kendig, 2000; Olsberg \& Winters, 2005). For example, while many older people are outright home owners, others still rent their homes or continue to pay mortgages, often on little fixed incomes. Some achieve financial independence through substantial superannuation balances while many others are wholly dependent on government pensions. An increasing divide within the older population is also observed overseas (O'Rand, 2006). There is a higher risk of social exclusion following increasing inequalities. Adopting a life course approach, Scharf, Phillipson and Smith (2005) and Naughtin (2008) argue some aspects of disadvantage are starting early in the life cycle and are having long term consequences. Thus, it is not surprising that social exclusion among older people may also persist.

This article aims to analyse social exclusion among older people in Australia with a focus on three elements. Firstly, it investigates the incidence of social exclusion among older Australians using selected indicators drawing on previous international and Australian literature. Secondly, the article considers whether an older person experiencing social exclusion at one time is more likely to experience it again at another time. Finally, the investigation examines the factors protecting older people from experiencing social exclusion.

The investigation of the issue is based on longitudinal Household, Income and Labour Dynamics in Australia (HILDA) Survey data and applies panel data estimation techniques.

The next section discusses a review of the conceptual framework of social exclusion. This is followed by an examination of the data, construction of variables and the methodology. Section four presents results and discussions, and the last section concludes.

\section{Conceptual Framework}

Drawing from a conceptual framework of 'social exclusion', literature usually differentiates between domains (outcomes) and drivers of social exclusion. The relationship between them is complex and sometimes outcomes may double up as drivers (see, for example, discussion in Bradshaw, Kemp, Baldwin, \& Rowe, 2004).

A domain refers to the discrete measure axis along which incidence of social exclusion is manifest. A domain includes a set of indicators on what activities a person does or does not do, can do or cannot do (such as whether a person is able to work or study) and her/his perceived opinion about her/his wellbeing (such as whether a person would be able to pay bills on time).

The domains usually discussed in the literature include material resources, social relations, participation, civic activities, access to basic services such as decent housing and public transport, information and local amenities, and the domains sometimes also include health (Barnes, Blom, Cox, Lessof, \& Walker, 2006; Kneale, 2012; Scharf, Phillipson, \& Smith, 2005). Levitas et al. (2007), who look at stages of life cycle including older people, have specified those domains also cover living environment (housing quality, homelessness, neighbourhood safety, neighbourhood satisfaction and access to open space). Crime, harm and criminalisation are also incorporated, including the risk of abuse at home and exposure to bullying, harassment and discrimination.

Lui et al. (2011) have examined social exclusion in the case of social workers and identified domains that are important for Australian older people. These domains include economic deprivation, cumulative disadvantage, social participation, civil engagement and cultural recognition. In contrast, Saunders, Naidoo and Griffiths (2007, p. 75) investigate three domains of exclusion: disengagement, service exclusion and economic exclusion. Disengagement takes forms such as no regular social contact with other people, no participation in community activities and could not pay one's way when out with friends. Service exclusion is defined as no access to a local doctor or hospital, no access to a bank or building society and inability to make electricity, water, gas and telephone payments. The third domain, economic exclusion, refers to not having $\$ 500$ in emergency savings and having not spent $\$ 100$ on a special treat in the last year. Saunders et al. (2007) find that deprivation declines across the three broad age categories (i.e., under 30, 30-64, and 65 and over), and older couples have the lowest level of deprivation among all family types examined.

On the other hand, a driver usually refers to a risk or condition that would increase the likelihood of a person to experience disadvantage in a particular domain and thus may lead to social exclusion. Drivers 
usually include demographic factors such as gender, age, educational attainment and also living arrangements. The drivers that increase the likelihood of social exclusion are considered risk factors, whereas the factors that are associated with lowering the likelihood of social exclusion are viewed as protective factors. For example, having low educational attainment as a driver may increase the likelihood of a person for not working in the future (participation domain).

Barnes, Blom, Cox, Lessof and Walker (2006) have found that social exclusion tends to increase with age, with those 80 years and above being more prone to exclusion. Further, living arrangements matter, with those who live alone (Saunders et al., 2007) or have no children, have poor mental or physical health and no access to a private car or lack of access to public transport are more vulnerable. Older people living in rental accommodation, having a low income and/or reliance on welfare and no access to a telephone are also more prone to experiencing social exclusion (and these may not only be limited to older people).

Health, in particular, is sometimes included as a domain of social exclusion (for example, Levitas et al., 2007, p. 10) and can also be viewed as a driver. For instance, Shields and Martel (2006) consider health as an important driver for successful ageing while Baltes and Mayer (1999) and Tesch-Romer, Motel-Klingebiel and von Kondratowitz (2003) view it as a decisive determinant to undertaking daily functions or having a degree of autonomy in old age. In this article, we take the second approach.

Kneale (2012) is among a few who examine the drivers of social exclusion particularly for older people using a multivariate model. Kneale (2012) includes various demographic and socioeconomic characteristics (such as age, gender, ethnicity, living arrangements, number of children, educational qualifications, health status, income level and housing tenure). In this article, we try our best to avoid the duplication between domains and drivers, as drivers focus much on the conditions that lead to persistence in terms of social exclusion.

The literature also argues that social exclusion can happen on multiple occasions and in a dynamic setting. Multiple occasions of social exclusion tend to indicate a more disadvantaged condition. Social exclusion can occur at one particular time and persist or be repeated another time, even within one stage of the life cycle. The availability of longitudinal data has allowed social exclusion to be measured for longer periods of time.

Scutella, Wilkins and Horn (2009, p. 29) proposed a continuum of exclusion with five levels: (1) not excluded (i.e., no domain of exclusion at any point in time); (2) at risk of exclusion (i.e., one or multiple domains of disadvantage at one point in time); (3) marginally excluded (i.e., one or multiple domains of exclusion at various points in time); (4) at risk of chronic exclusion (i.e., a number of domains of disadvantage in various points in time; (5) chronically excluded (i.e., multiple domains of disadvantage and persistently excluded). Poggi (2007), in contrast, only classifies the degree of social exclusion into three broad categories: not excluded, excluded (defined as being deprived of two or more aspects of relevant functioning), and persistently excluded (i.e., experiencing exclusion in subsequent years or for multiple spells). In this article we generally take this simpler approach.

Figure 1 provides a summary of the conceptual framework that is adopted in this article. Our main interest is to examine the protective factors against older people in Australia experiencing social exclusion. Four domains of social exclusion are considered, including material resources, participation, social support and community engagement. Following Poggi (2007), social exclusion is defined as being excluded in at least two domains, which means at least half of the total four domains in our study. On the other hand, following the literature and data availability, the main drivers of social exclusion considered in this article include demographic factors, place of residence, human capital, housing tenure/condition, labour market history, income, health status, living arrangements and caring role.

In the literature, the expected relationships between social exclusion and some of its drivers are clear but this is not always the case. For instance, higher human capital/educational attainment, longer labour market attachment, higher income, better health and absence of long term health conditions, no caring responsibilities, home ownership, and living with other household members are associated with a lower likelihood of social exclusion for older people. In contrast, a higher risk of social exclusion is found among immigrants and older cohorts. The association between place of residence and social exclusion is still not clear. These relationships will be tested empirically in the next section.

The initial condition of social exclusion at wave 1 and the previous year's condition of social exclusion are also included, in order to measure the persistence of social exclusion.

\section{Data, Variable Construction and Methodology}

\subsection{Data}

The dataset used for this research is the HILDA Survey, which contains a representative sample of the Australian population, including 19,914 individuals in 7,682 households at its first wave in $2001 .^{2}$ HILDA is a longitudinal survey conducted annually since 2001, and the current research is based on the first eight waves

2 For further details of the HILDA Survey, refer to http://www.melbourneinstitute.com/hilda 
(2001-2008). HILDA is fairly successful in maintaining a low wave-on-wave attrition rate; for instance, the attrition rate for Wave 8 was just 4.8 per cent (Melbourne Institute of Applied Economic and Social Research, 2009). For the current purpose of understanding social exclusion among older people, the working sample of this research is restricted to 2,162 individuals aged 55 years or older in 2001 who participated in all eight waves of the survey (a balanced panel). ${ }^{3}$ Fifty four per cent are female. In some analyses the sample is disaggregated into a younger cohort (55-64 years at wave

${ }^{3}$ Note that at the first wave 3,683 people aged 55 or older had been successfully interviewed. Considering the age of the sample, the exclusion from the working sample of a balanced panel is likely to be non-random; for instance, older people and people in poor health are more likely to be excluded and they are also likely to be subject to a higher risk of social exclusion. As such, the restriction to a balanced sample, though necessary, may lead to an underestimation of the persistence of social exclusion.
$1, n=1,102$ ) and an older group (65 years and over at wave $1, n=1,060$ ). This is to see if the pattern of exclusion differs across different cohorts of older people, differentiating between those who are considered in the pre-retirement age group (below 65) and those who are at retirement age of 65 years or above.

To measure incidence and persistence of social exclusion, the following steps are required:

1. To identify relevant domains and key indicators

2. To set up a threshold for how many indicators of disadvantage are necessary for defining exclusion in each domain

3. To choose a threshold for how many domains of exclusion are used as a measure of comprehensive social exclusion at a particular time (incidence of social exclusion)

4. To set up a threshold for social exclusion across multiple times (persistence of social exclusion)

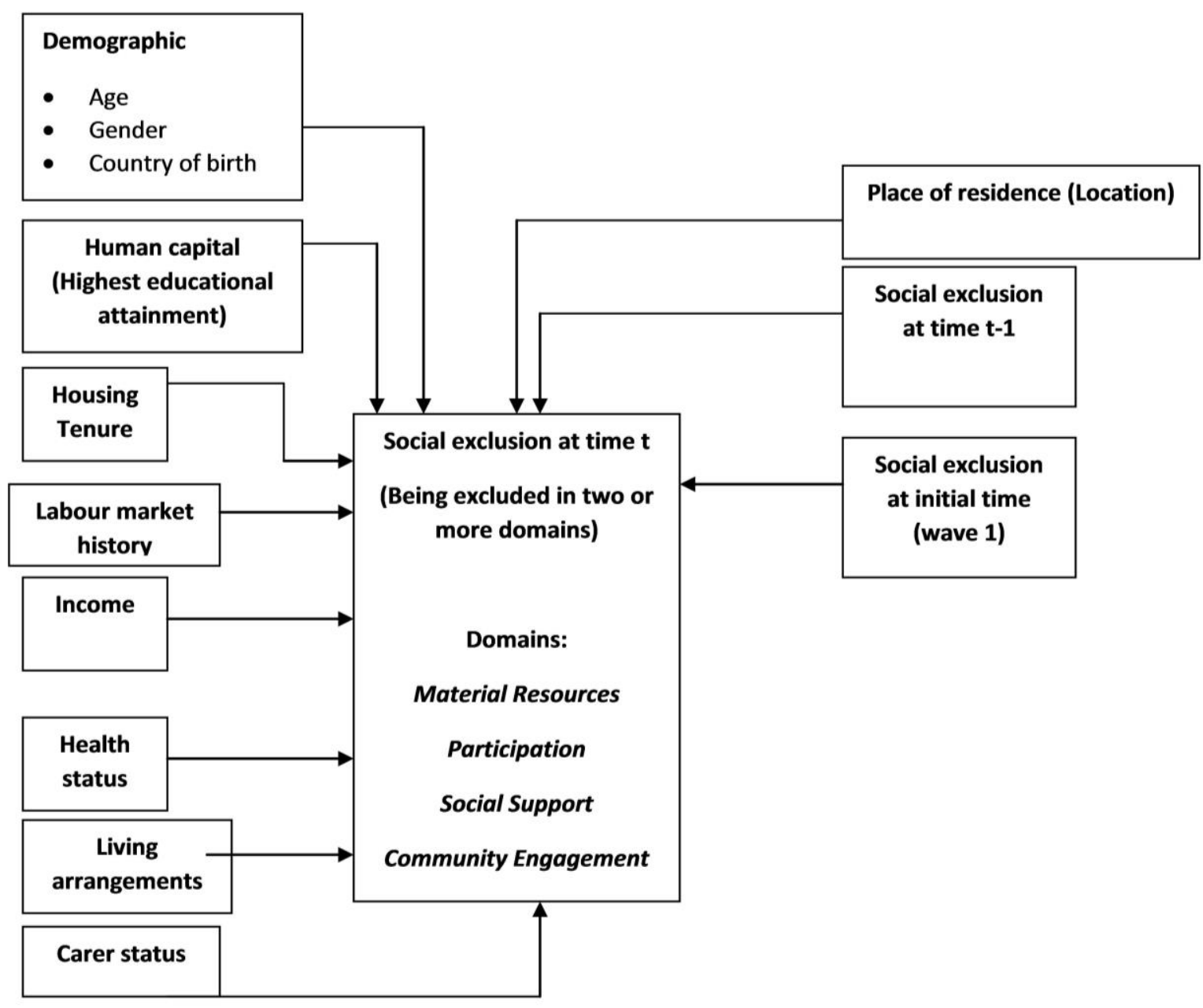

Figure 1. Conceptual framework of social exclusion of older people in Australia. Source: Authors' summary. 


\subsection{Variable Construction}

\subsubsection{Key Domains and Indicators of Social Exclusion}

(Steps 1, 2 and 3)

Informed by the literature, key indicators were selected to reflect social exclusion in four key domains: material resources, economic and social participation, social support, and community engagement. ${ }^{4}$ Other domains identified in the literature such as access to services and access to transport, although important, were not covered due to data limitations. For the purpose of this research, health status has been chosen as a driver rather than an indicator of social exclusion as health issues are more related to the causes of social exclusion in old age. Except for labour market and studying indicators included in the domain of economic and social participation, most of the indicators reflect older people's perceived opinion about their wellbeing. We acknowledge the limitations of using the pre-existing indicators of the HILDA dataset. However, we think that HILDA is the most suitable database for this research as it contains detailed characteristics of its respondents and due to its longitudinal nature, which are important to answer the research aims of the study. Based on the guidance of the previous literature and how the variables are distributed, generally we are trying to focus on the bottom-tail of the distribution, which usually covers those who are at the highest risk of exclusion on a particular indicator at a particular point in time. The key domains and indicators are specified as follows:

Exclusion in material resources was identified by the presence of any of the following indicators, as any single one of them is sufficient to reveal a lack of access to essential material resources: ${ }^{5}$

- Could not pay electricity, gas or telephone bills on time

- Could not pay the mortgage or rent on time

- Asked for financial help from friends or family

- Pawned or sold something

- Was unable to heat home

- Went without meals

- Asked for help from welfare/community organisations

- Could not raise $\$ 2,000$ in emergency within a week.

\footnotetext{
${ }^{4}$ It should be noted that almost all the selected indicators of the domains, especially those based on self-completion questionnaires, have some missing values, which are generally treated as negative for the aspect of exclusion in question.

${ }^{5}$ The first seven indicators refer to incidence in a calendar year due to a shortage of money.
}

Exclusion in economic and social participation was identified as all of the following indicators being true at the time of interview: ${ }^{6}$

- Not worked for wage or salary

- Not worked in own business

- Not enrolled in a full-time course

- Not enrolled in a part-time course

- Not an active club member

- Contact with friends/relatives once a month or less

- Not volunteering.

Exclusion in social support was defined as half or more of the following indicators being true: ${ }^{7}$

- I don't have anyone that I can confide in (agree)

- There is someone who can always cheer me up when I'm down (disagree)

-I seem to have a lot of friends (disagree)

- I have no one to lean on in times of trouble (agree)

- I often need help from other people but can't get it (agree)

- I enjoy the time I spend with the people who are important to me (disagree)

- People don't come to visit me as often as I would like (agree)

- When I need someone to help me out, I can usually find someone (disagree)

- When something's on my mind, just talking with the people I know can make me feel better (disagree)

- I often feel very lonely (agree).

Exclusion in community engagement was identified as true in any of the following indicators: ${ }^{8}$

- Dissatisfaction-feeling part of your local community

- Dissatisfaction - the neighbourhood in which you live

- Dissatisfaction-how safe you feel.

\footnotetext{
${ }^{6}$ Considering their age, people in the sample may live an inclusive life with active engagement in any of the activities like working, studying, volunteering or socialising.

7 The participants are asked to pick a number between 1 (strongly disagree) and 7 (strongly agree) about the statements. Thresholds for exclusion in this domain are mainly chosen around the top or bottom decile of the distribution of each indicator; the key findings are not particularly sensitive to a slightly different alternative.

${ }^{8}$ The participants are asked to pick a number between 0 (totally dissatisfied) and 10 (totally satisfied) about their satisfaction with feeling part of the local community, satisfaction with their neighbourhood, and how safe they feel. They are classified as dissatisfied if they picked a number smaller than 5 .
} 
This article focuses on social exclusion in multiple domains, which indicates a more disadvantaged group and is of particular policy interest. After a series of exercises and validation, an older person is considered as socially excluded if this person experiences exclusion in multiple domains (at least two domains, following Poggi, 2007). Thus, incidence is calculated as a proportion of the older people who are excluded in multiple domains. ${ }^{9}$ Next we discuss how to define the persistence of social exclusion.

\subsubsection{Definition and Measurement of Persistence} (Step 4)

Persistence of social exclusion can be viewed in different ways, for instance following Poggi's (2007) framework:

(1) an older person who experienced exclusion again if he/she experienced exclusion in the previous year, or alternatively,

(2) an older person who experienced exclusion over most of the time observed, that is, five or more years over the eight years in the sample.

Persistence of exclusion can be examined in each of the four domains, or in multiple (at least two) domains. In the descriptive analysis in section four, results are reported for both measures. In both cases, the focus is on the persistence of exclusion in multiple domains, which tends to indicate a more disadvantaged situation. However, in multiple regression analysis, results are mainly reported for the first measure (i.e., experiencing social exclusion in consecutive years) utilising a dynamic model. If not otherwise specified, social exclusion refers to exclusion in multiple domains later on in this article.

\subsubsection{Methodology}

This article uses a dynamic panel logit model, following Poggi (2007). Using the first definition of persistence of social exclusion, which is whether an older person experiences exclusion again if they experienced exclusion in the previous year, the dependent variable is the presence of social exclusion at a particular time. Panel data analysis is applied not only to incorporate unobserved heterogeneity across older people but also to control omitted time variant variable bias (captured in the wave dummies). A random effects panel data model is used instead of fixed effects, to allow the examination of time invariant variables that are important for social exclusion such as gender and country of birth. The logit model is chosen and the dependent

\footnotetext{
${ }^{9}$ Note that apart from the aforementioned reasons, reaching a reasonable cell size (sample size) is also considered in defining exclusion in a domain.
}

variable is set up in a discrete format. It is equal to one if an older person experiences exclusion in multiple domains and zero otherwise. The sample contains 8 waves of data (balanced panel), observing from $t=1$ to $t=8$. The conditional probability that social exclusion happens can be written as follows:

$$
P\left(y_{i t}=1 \mid y_{i t-1}, \ldots, y_{i o}, z_{i,} c_{i}\right)=\phi\left(z_{i t} \gamma+\beta y_{i o}+\rho y_{i t-1}+c_{i}\right)
$$

Where the functional form of $\phi$ is a logistic distribution, and the dependent variable $y_{i t}$ is a condition which specifies whether a particular older person $\mathrm{i}$ is socially excluded at time t. $\gamma, \beta$ and $\rho$ are the parameters to be estimated. ${ }^{z_{i}}$ and ${ }^{z_{i t}}$ are, respectively, vector of time-constant and time-varying explanatory variables, and $c_{i}$ is the individual fixed effect (Poggi, 2007, p. 64).

The dynamic relationship exists as there is a presence of lag of the dependent variable which serves as the explanatory variable. Thus, social exclusion in year $t$ is determined by the lag of the social exclusion in year t-1. If $\rho>0$, this will mean that experiencing social exclusion in year $\mathrm{t}-1$ will increase the likelihood of experiencing exclusion at time $t$. The initial value of the social exclusion status at to (wave 1 ) is also included. If $\beta>0$ this indicates that experiencing social exclusion in year t0 will increase the likelihood of experiencing exclusion at time $t$.

As illustrated in Figure 1, social exclusion in year $\mathrm{t}$ is also determined by the following drivers or factors: demographic factors (age, gender and country of birth), educational attainment, housing tenure (home ownership), labour force participation history, income, disability status, living arrangements, carer status and location. To allow for a non-linear relationship between social exclusion and age, a quadratic function of age is used. Proportion of time not working since finished full-time education is included to reflect labour force participation history, and is included in the equation in the natural logarithm format.

Household disposable income is expressed in AUD \$2001 and equivalised to take into account differences in household size and composition. A modified Organisation for Economic Cooperation and Development (OECD) equivalence scale is used to equivalise the disposable household income which assigns the values of 1.0 for the first adult, 0.5 for each of the remaining adults and 0.3 for each dependent child in the household. Equivalised household disposable income is included in the equation in the natural logarithm format. Carer status refers to whether the person is responsible for caring for disabled people or other older people. The model also includes two location variables: (i) 
State and, (ii) Socio-Economic Indexes for Areas (SEIFA) 2001 Index of Relative Socio-Economic Advantage/Disadvantage. The SEIFA index shows the socio-economic condition attached to the place of residence. It is categorised in quintiles, and the lowest quintile refers to the most disadvantaged areas. The analysis focuses on personal characteristics of older persons rather than government interventions.

\section{Results and Discussions}

4.1. Incidence of Social Exclusion
As can be seen in Table 1 on the Descriptive Statistics, which answers the first aim of the research, around 9.8 per cent of older people experienced incidence of social exclusion (please also see Appendix 2 for incidence of exclusion by wave). The disaggregation across cohorts (results not shown) indicates that the incidence of social exclusion is 10 per cent for the younger cohort, which is not much different from the 9.5 per cent incidence rate among the older cohort. However, the persistence perspective is not so rosy, as we discuss below.

Table 1. Descriptive statistics of key variables in regressions.

\begin{tabular}{|c|c|}
\hline Key variables & Mean/proportion \\
\hline \multicolumn{2}{|l|}{ Incidence of social exclusion (SE): } \\
\hline SE at all waves & 9.8 per cent \\
\hline SE at wave 1 & 11.0 per cent \\
\hline SE at the previous wave & 9.5 per cent \\
\hline \multicolumn{2}{|l|}{ Age } \\
\hline Age (years) & 69.3 \\
\hline Age sq & 4865.0 \\
\hline \multicolumn{2}{|l|}{ Gender (omitted male) } \\
\hline Female & 53.9 per cent \\
\hline \multicolumn{2}{|l|}{ Living arrangements (omitted living alone) } \\
\hline Living with partner only & 56.9 per cent \\
\hline Living with children only & 5.1 per cent \\
\hline Living with partner and children & 11.8 per cent \\
\hline \multicolumn{2}{|l|}{ Country of birth (COB) (omitted born in Australia) } \\
\hline COB: Main English Speaking Countries (MESC) & 13.8 per cent \\
\hline COB: other countries & 17.5 per cent \\
\hline \multicolumn{2}{|l|}{ Education (omitted bachelor degree or above) } \\
\hline Diploma or certificate & 28.4 per cent \\
\hline Year 12 & 7.0 per cent \\
\hline Year 11 or below & 53.6 per cent \\
\hline \multicolumn{2}{|l|}{ Carer status (omitted not caring for others) } \\
\hline Caring for others with disability or elderly & 3.3 per cent \\
\hline \multicolumn{2}{|l|}{ Housing tenure (omitted other tenures) } \\
\hline Home owner or currently paying off mortgage & 83.3 per cent \\
\hline \multicolumn{2}{|c|}{ Health status (omitted having long term health condition, disability or impairment) } \\
\hline Not having any long term health condition, disability or impairment & 54.2 per cent \\
\hline \multicolumn{2}{|l|}{ Labour market history } \\
\hline Proportion of time not working & 29 per cent \\
\hline \multicolumn{2}{|l|}{ Income } \\
\hline Equivalised household disposable income (real terms in AUD\$2001) & 24,242 \\
\hline \multicolumn{2}{|l|}{ State (omitted New South Wales) } \\
\hline State: Victoria & 26.8 per cent \\
\hline State: Queensland & 17.0 per cent \\
\hline State: South Australia & 7.9 per cent \\
\hline State: Western Australia & 8.6 per cent \\
\hline State: Tasmania & 2.3 per cent \\
\hline State: Northern Territory and ACT & 1.3 per cent \\
\hline
\end{tabular}

Note: Based on balanced panel of HILDA data. Weighted with responding person longitudinal weights. SE is defined as social exclusion in multiple domains. Source: Authors' calculation. 


\subsection{Persistence of Social Exclusion}

Table 2 below shows the persistence of social exclusion. Column A shows the proportion or incidence of people experiencing exclusion if they experienced exclusion in the previous year (among the 9.8 per cent of the older people discussed earlier). Column B provides an alternative measure of persistence, which shows the proportion of the older people who experienced exclusion in five or more years over the eight years in the whole HILDA sample.

The persistence of exclusion varies across domains and sub-samples. Exclusion in material resources and participation is relatively more persistent over two consecutive years than exclusion in the other two domains. Interestingly, exclusion among the older subsample (mostly over the age eligible for the government Age Pension) is relatively less persistent on all measures except participation, possibly indicating the positive role of the Age Pension and related benefits provided by the government. Higher persistence of exclusion on the participation domain for the older subsample may reflect lower attachment to the workforce for those aged over 65 years, which is not fully substituted by higher participation in social activities.

Table 2 indicates a relatively high persistence of exclusion among people who experienced exclusion in multiple domains, a more disadvantaged group in the sample. Responding to the second research aim, 45 per cent of those who experienced exclusion in two or more domains in one year reported the same situation in the previous year (persistence). So, while only about 9.8 per cent of the sample experienced social exclusion, almost half of this group experienced persistent social exclusion.

\subsection{Drivers of Social Exclusion}

The estimation is conducted in stages (see Appendix 1 for full estimation results) in order to answer our third research question, which is to examine factors protecting older people from experiencing social exclusion.
The base model, Model 1, only includes social exclusion status at wave 1 (initial exclusion status) and exclusion at the previous wave (lagged exclusion status). Extra control variables are added in Models 2 and 3, while Model 4 or the complete model includes all explanatory variables specified in Figure 1 and is estimated using the entire sample as well as separately using the two sub-samples (young and older cohorts).

Table 3 reports the corresponding odds ratios of Model 4, estimated respectively using the entire sample, the younger cohort and the older cohort. An odds ratio larger than 1 indicates a positive relationship between the independent variable in question and the likelihood of experiencing social exclusion (dependent variable), and an odds ratio smaller than 1 indicates a negative relationship. The factor may be considered as a risk factor for experiencing social exclusion in the former case, and a protective factor from social exclusion in the latter case.

As shown in Appendix 1, both the coefficients of the lagged exclusion (in the previous year) and the initial exclusion status are consistently large in size and statistically significant, no matter which other factors are controlled for.

The first column of Table 3 shows that among all older people in the sample, experiencing social exclusion at wave 1 increases the odds of experiencing exclusion again later by approximately 30 times, suggesting a strong state dependence in relation to social exclusion. The odd of recurrence of exclusion nearly doubles if social exclusion was experienced in the previous year, revealing a significant persistence of social exclusion among this group.

While the previous descriptive statistics show that 45 per cent of those who experienced social exclusion in one year have experienced the same situation in the previous year, this regression estimates the likelihood of this situation happening. The likelihood is around 2 times greater than for those who do not experience social exclusion. Table 3 also reaffirms that the likelihood of persistence of exclusion is larger for the younger cohort than for the older one.

Table 2. Persistence of social exclusion.

\begin{tabular}{lcccccc}
\hline \multirow{2}{*}{\multicolumn{1}{c}{ Domain }} & \multicolumn{3}{c}{ Measure A } & \multicolumn{2}{c}{ Measure B } \\
\cline { 2 - 6 } & $\begin{array}{c}\text { Proportion excluded among those } \\
\text { who experienced exclusion the } \\
\text { previous year (per cent) }\end{array}$ & $\begin{array}{c}\text { Proportion excluded in five or more } \\
\text { years (per cent) }\end{array}$ \\
\cline { 2 - 7 } & $\begin{array}{c}\text { Younger } \\
\text { Material resources }\end{array}$ & Older & Total & Younger & Older & Total \\
Participation & 60.1 & 44.9 & 53.3 & 11.1 & 7.5 & 9.3 \\
Social support & 52.6 & 58.1 & 55.9 & 3.4 & 5.5 & 4.4 \\
Community engagement & 37.3 & 33.4 & 35.4 & 3.6 & 25 & 3.1 \\
Exclusion in two or more domains & 49.5 & 45.7 & 47.6 & 7.3 & 7.9 & 7.6 \\
\hline \multicolumn{1}{c}{$N$} & 50.3 & 39.6 & 45.1 & 5.8 & 4.2 & 5.0 \\
\hline
\end{tabular}

Note: Based on a balanced panel of HILDA data. Weighted with responding person longitudinal weights. Source: Authors' calculation. 
Table 3 Regression results and odds ratios.

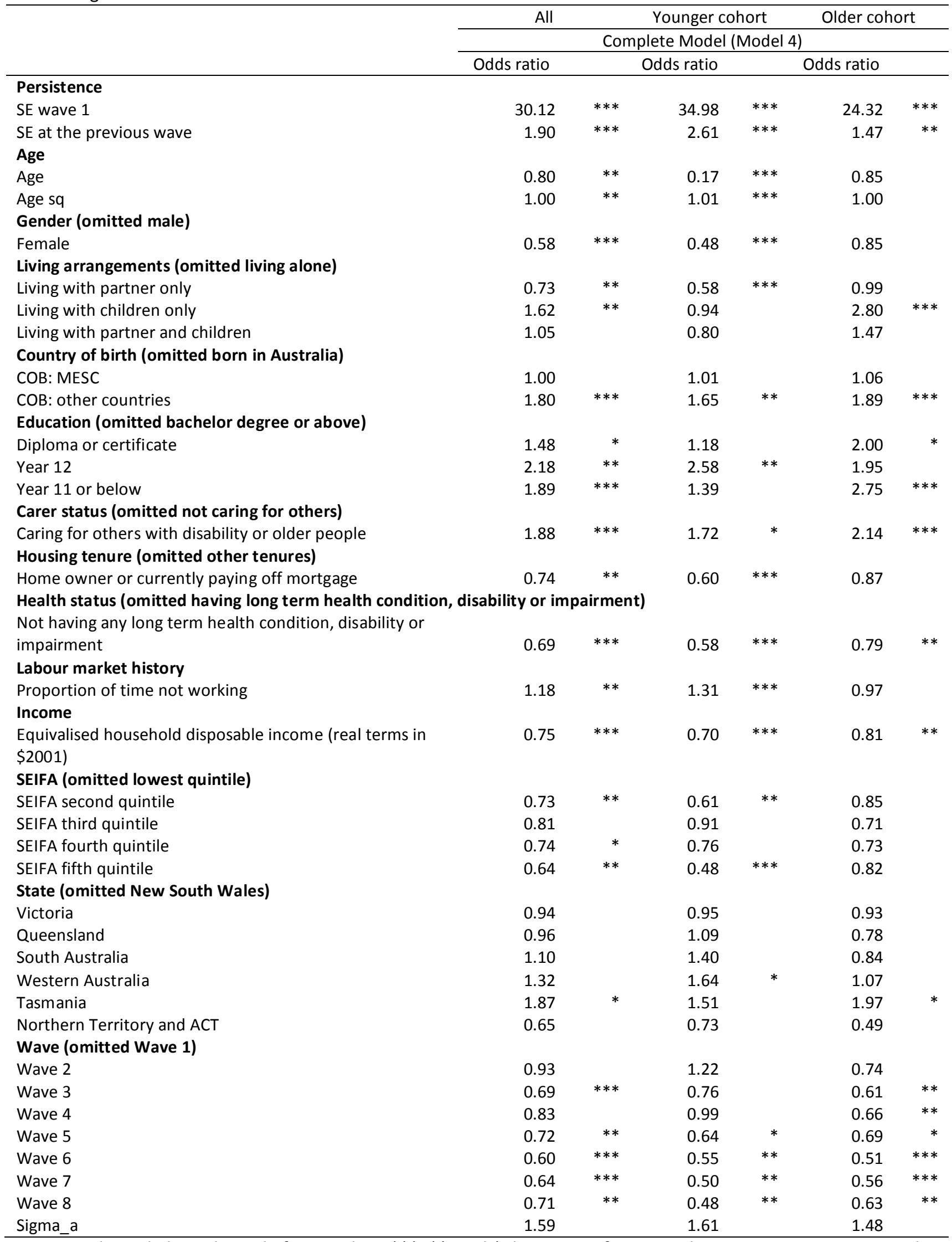

Note: Based on a balanced panel of HILDA data. ${ }^{* * *},{ }^{* *}$, and ${ }^{*}$ denote significance at the 1 per cent, 5 per cent and 10 per cent levels, respectively. Source: Authors' calculation. 
The results reported in the first column of Table 3 suggest that among all the older people in the sample, the following factors are associated with significantly higher risks of social exclusion: caring for others with a disability or older people, own disability, poor educational attainment, less engagement in employment since finishing full-time education, and living in the most disadvantaged areas.

So, older people who are more disadvantaged, who are not healthy, having lower socio-economic status and living in the lower socio-economic neighbourhoods are associated with higher risks of social exclusion. Living with dependent children only (under 15 years of age or full time students aged 15-24) is also associated with higher risk of social exclusion, which may reflect both financial and non-financial commitments from the older parents in raising their children. The results also show that older people who were born in non-Main English Speaking countries may be more disadvantaged than others. ${ }^{10}$

These findings are in general in line with the results of Kneale (2012) who finds that ethnicity, living arrangements and health status are important risk factors. Kneale (2012) finds that being non-white, living alone and poor health are the significant risk factors for social exclusion among the older people while living with children only and being a carer are also risk factors of social exclusion but not significant.

However, comparing the results of the first column of Table 3 with those of the other two columns reveals that except for the risk factors of born in non-Main English Speaking Countries, own disability, and caring for others with disability or elderly, which are shared by both cohorts, other factors only dominate among one cohort. For instance, less engagement in employment in the past, and living in socio-economically most disadvantaged areas are significant risk factors only for the younger cohort, whereas living with children only is significant only for the older cohort. Education effects also differ by cohorts.

For older people in the sample as a whole, the following factors are associated with significantly lower risks of social exclusion: female, living with partner only, having a bachelor degree or above level of education, home ownership, better health, more time in employment since leaving full-time education, higher income, and living in socio-economically most advantaged areas. The results are in line with Kneale (2012), particularly in

\footnotetext{
${ }^{10}$ For example, our calculation of the Australian Census data 2006 shows that the proportion of migrants who were born in other countries (non-Main English speaking countries) and having educational level of bachelor degree or above and working in low skilled occupations were around 21 per cent, while it was less than half of this figure for those who are born in Australia and in the Main English speaking countries.
}

regard to living with partner only, home ownership, better health and higher income. So, those older people who are healthy, having higher socio-economic background and living in the higher socio-economic areas are typically less prone to social exclusion.

When the two cohorts are analysed separately, income, education and health appear to be common protective factors. However, female, living with partner only, homeownership, and better socio-economic circumstances as indicated by the SEIFA index are mainly protective for the younger cohort; for the older cohort, they do not matter much.

Age shows different effects for the two cohorts of older people. When the younger cohort is used (aged 55-64 years in 2001; see results in Column 2 of Table $3)$, the risk of social exclusion appears to be U-shaped in terms of age, minimising around age 62 . In contrast, for the older cohort (aged 65 years or older in 2001) the risk of exclusion does not significantly vary with age. However, when the whole sample is used for estimation, a U-shaped relation is also observed between the risk of social exclusion and age, minimising around age 78. Interestingly, the odd ratios of the dummy variables for the waves suggest that there is no clear pattern to indicate if social exclusion increases or decreases over time.

In addition, similar to Poggi's (2007, p. 65) findings, this study found that even when the regressions have taken into account the explanatory variable, the estimated sigma_a $>1$. This means that there is still some unobserved heterogeneity that cannot be explained by the explanatory variables. Perhaps this reflects the fact that some non-personal or location characteristics may affect social exclusion but are not controlled for in the model, for example, policy intervention variables such as the Age Pension.

\section{Conclusions}

The existing literature on social exclusion among older people, though relatively limited, suggests that disadvantage among older people is cumulative in nature. As such, disadvantaged older people may be subject to a higher risk of social exclusion and persistence of social exclusion. This is the strength of our study, which aims to improve understanding of social exclusion among senior Australians using a nationally representative survey and focusing particularly on potential protective factors.

We have answered three research questions in this article. First, in terms of the incidence of social exclusion, the descriptive analysis showed that only a small proportion of older people were socially excluded in multiple domains at a point in time (less than 10 per cent).

Second, among this fraction of people, about 45 per cent had an experience of social exclusion in multiple domains in the previous year (persistence).The results 
of multivariate analysis also confirmed a high persistence of social exclusion in multiple domainsexclusion in the previous year significantly increases the likelihood of experiencing exclusion in the current year. Interestingly, the younger cohort, that is, people aged 55-64 years in 2001, showed a higher persistence of social exclusion in multiple domains compared to the older cohort. This contradicts expectations, given that participation and engagement tends to be lower as people age. The results may have complex reasons, and policy intervention targeting older people on low incomes may have some role to play; however, as the Age Pension and related benefits in Australia are widely available based on means tests, it is difficult to isolate the effects of the Age Pension and in-kind benefits from the impact of age and financial disadvantage. Further exploration is warranted.

Regarding the third research aim, the regression analysis shows that higher education and income, as well as better health and previous employment experiences are important protective factors for older Australians against social exclusion. Those who are at risk or socially excluded mostly have experienced low quality of life or many disadvantages. It will be interesting to see whether these risks have been developing prior to older age, and whether the social exclusion that is experienced at older age has been experienced during younger ages of the life course. The literature has argued the importance of a life course perspective in undertaking research on older people, and how the life course can determine stratification and social inequality amongst older people. Future research is warranted and this will provide us with a context for understanding and explaining the heterogeneity in the wellbeing of older Australians. Australian people are living longer (life expectancy at birth is now 80.1 years for males and 84.3 years for females) and the qualifying age for the Age Pension has been proposed to rise to 70 years. Policy interventions to promote quality of life and wellbeing at the later ages are increasingly important.

Note that, as indicated above, this article has not taken into account government interventions such as the provision of Age Pension and other government benefits, which are expected to contribute to reducing the likelihood of social exclusion among older people. The issue is left for future study. In addition, we acknowledge a potential data limitation of this study, which is based on the single available source data of HILDA. However, we believe this data is among the best available longitudinal micro data relevant for answering the research questions and the empirical findings are consistent with the results of the previous studies in other countries. Given the complexity of measuring social exclusion and the different patterns of incidence and persistence of exclusion across age cohorts, more efforts are required to further develop an age-related social exclusion framework to reflect different life circumstances across stages of the life cycle and to improve the data collection of relevant contents for future analysis.

\section{Acknowledgements}

This article uses unit record data from the Household, Income and Labour Dynamics in Australia (HILDA) Survey. The Household, Income and Labour Dynamics in Australia (HILDA) Survey was initiated and is funded by the Australian Government Department of Social Services (DSS), and is managed by the Melbourne Institute of Applied Economic and Social Research (Melbourne Institute). The findings and views based on these data should not be attributed to either DSS or the Melbourne Institute.

An earlier version of this paper was presented at the HILDA Conference 2011 in Melbourne. The authors are grateful to comments and feedback from the Conference's participants. The authors also would like to thank valuable input from colleagues at NATSEM, IGPA, University of Canberra and Commonwealth of Australia Department of Social Service and literature assistance from Ms Gabriela D'Souza, previously from University of Canberra.

\section{Conflict of Interests}

The authors declare no conflict of interests.

\section{References}

Baltes, P. B., \& Mayer, K. U. (Eds.). (1999). The Berlin aging study: Aging from 70 to 100. Berlin: Cambridge University Press.

Barnes, M., Blom, A., Cox, K., Lessof, C., \& Walker, A. (2006). The social exclusion of older people: Evidence from the first wave of the English Longitudinal Study of Ageing (ELSA). London, UK: Office of the Deputy Prime Minister.

Bradshaw, J., Kemp, P., Baldwin, S., \& Rowe, A. (2004). The drivers of social exclusion: $A$ review of the literature (Breaking the cycles series). London: Social Exclusion Unit, Office of the Deputy Prime Minister.

Commonwealth of Australia. (2010). Intergenerational report-Australia to 2050: Future challenges. Canberra: The Treasury.

Faulkner, D. (2007). The older population and changing housing careers: Implications for housing provision. Australasian Journal on Ageing, 26(4), 152-156.

Hayes, A., Gray, M., \& Edwards, B. (2008). Social inclusion: Origins, concepts \& key themes (Report prepared for Australian Institute of Family Studies for the Social Inclusion Unit). Canberra: Department of Prime Minister and Cabinet.

Kendig, H. (2000). Ageing and the built environment. In P. Troy (Ed.), Equity, environment, efficiency: Ethics 
and economics in urban Australia (pp. 97-109). Melbourne: Melbourne University Press.

Kneale, D. (2012). Is social exclusion still important for older people? London: The International Longevity Centre - UK (ILC-UK).

Lenoir, R. (1974). Les exclus: Un Français sur dix, 13. Paris: Seuil.

Levitas, R., Pantazis, C., Fahmy, E., Gordon, D., Lloyd, E., \& Patsios, D. (2007). The multi-domain analysis of social exclusion. London: Social Exclusion Task Force.

Lui, C. W., Warburton, J., Winterton, R., \& Bartlett, H. (2011). Critical reflections on a social inclusion approach for an ageing Australia. Australian Social Work, 64 (3), 266-282.

McNamara, J., Tanton, R., Daly, A., \& Harding, A. (2009). Spatial trends in the risk of social exclusion for Australian children: Patterns from 2001 to 2006. Child Indicators Research, 2(2), 155-179.

Melbourne Institute of Applied Economic and Social Research (2009). HILDA survey: Annual report 2009. Melbourne: Melbourne Institute of Applied Economic and Social Research, University of Melbourne.

Naughtin, G. (2008). Social inclusion and the older people. In Social Inclusion Down Under Symposium Proceedings. Melbourne: Brotherhood of St Laurence.

Olsberg, D., \& Winters, M. (2005). Ageing in place: intergenerational and intrafamilial housing transfers and shifts in later life (AHURI Final Report no.88). Melbourne: Australian Housing \& Urban Research Institute.

O'Rand, A. M. (2006). Stratification and the life course: Life course capital, life course risks \& social inequality. In R. H. Binstock \& Shanas. E. (Eds.), Handbook of aging \& the social sciences (pp.145-162). USA: Elsevier.

Phillipson, C., \& Scharf, T. (2004). The impact of government policy on social exclusion among older people. London: Office of the Deputy Prime Minister.

Poggi, A. (2007). Does persistence of social exclusion exist in Spain? Journal of Economic Inequality, 5(1), 53-72.

Saunders, P., Naidoo, Y., \& Griffiths, M. (2007). Towards new indicators of disadvantage: Deprivation and social exclusion in Australia. Sydney: Social Policy Research Centre, University of New South Wales.

Scharf, T., Phillipson, C., \& Smith, A. E. (2005). Multiple exclusion and quality of life amongst excluded older people in disadvantaged neighbourhoods. UK: Centre for Social Gerontology, Keele University.

Scuttella, R., Wilkins, R., \& Horn, M. (2009). Measuring poverty \& social exclusion in Australia: A proposed multidimensional framework for identifying socioeconomic disadvantage (Melbourne Institute Working Paper vol. 4, no. 9). Melbourne: Melbourne Institute of Applied Economic and Social Research.

Shields, M., \& Martel, L. (2006). Healthy living among seniors. Health Reports Special Issue (Supplement to vol. 16). Ottawa: Statistics Canada, Health Statistics Division.

Tanton, R., Harding, A., Daly, A., McNamara, J., \& Yap, M. (2010). Australian children at risk of social exclusion: A spatial index for gauging relative disadvantage. Population, Space and Place, 16(2), 135150.

Tesch-Romer, C., Motel-Klingebiel, A., \& von Kondratowitz, H. J. (2003). Quality of life. In A. Lowenstein \& J. Ogg (Eds.), Old age \& autonomy: The role of service system \& intergenerational family solidarity (pp.257-280) (OASIS Final Report). Israel: Center for Research \& Study of Aging, the University of Haifa.

United Kingdom Social Exclusion Unit Office of the Deputy Prime Minister. (2006). A sure start to later life ending inequalities for older people. A Social Exclusion Unit Final Report. London: Office of the Deputy Prime Minister.

United Nations. (2007). Literature review on social exclusion in the ESCWA region, economic \& social commission for Western Asia (ESCWA). New York: United Nations.

\section{About the Authors}

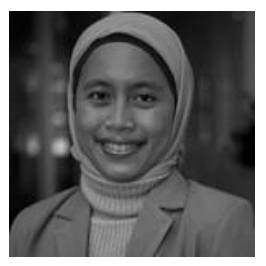

Dr. Riyana Miranti

Riyana Miranti is Senior Research Fellow at Institute for Governance and Policy Analysis, University of Canberra. She has strong research interests in the areas that focus on wellbeing and disadvantage, investigating issues of poverty and inequality for Australian communities and social exclusion affecting various population groups. She has been working extensively under several Australian Research Council (ARC) grants which focus much on wellbeing and disadvantage at small area level, including a project that focuses on children and youth social exclusion. 


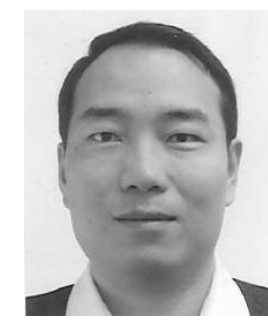

\section{Dr. Peng Yu}

Peng $\mathrm{Yu}$ is a senior research analyst of the Australian Government Department of Social Services. He obtained a PhD degree in Economics from the Australian National University. His previous research covers fertility, mortality, welfare reliance, retirement, participation and social inclusion issues. His current research interests focus on disadvantage, inequality and wellbeing. 
Appendix 1. Regression Results.

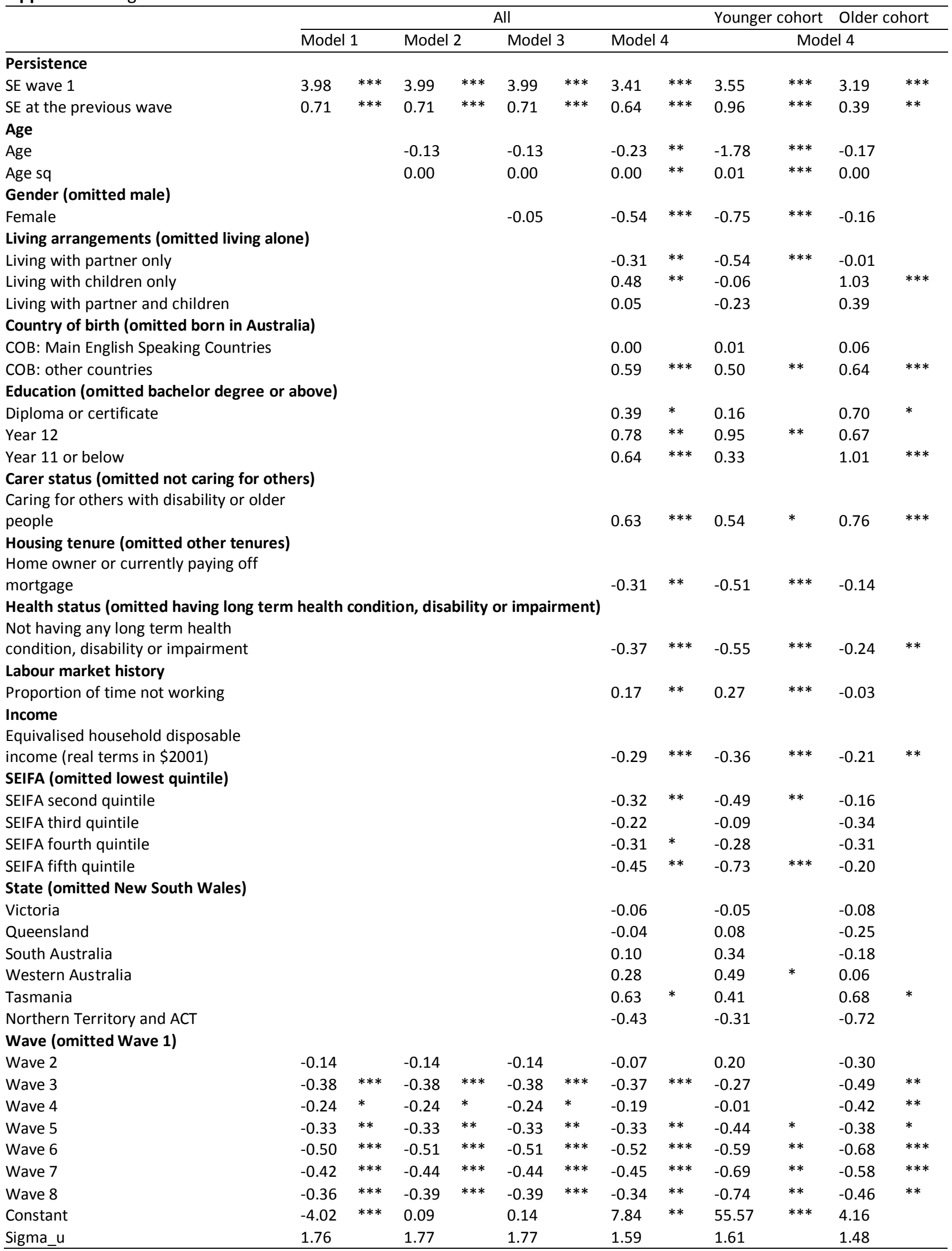

Note: Based on a balanced panel of HILDA data. $* * *, * *$, and $*$ denote significance at the 1 per cent, 5 per cent and 10 per cent levels, respectively. Source: Authors' calculation. 
Appendix 2. Incidence of social exclusion at a point in time (\%).

\begin{tabular}{|c|c|c|c|c|c|c|c|c|c|}
\hline & Wave 1 & Wave 2 & Wave 3 & Wave 4 & Wave 5 & Wave 6 & Wave 7 & Wave 8 & Total \\
\hline Material resources & 19.3 & 17.2 & 16.8 & 16.0 & 13.9 & 12.2 & 11.8 & 12.0 & 14.9 \\
\hline Participation & 8.0 & 9.4 & 7.8 & 9.6 & 10.2 & 10.9 & 10.4 & 14.0 & 10.0 \\
\hline Social support & 9.8 & 10.3 & 10.4 & 10.4 & 11.0 & 7.2 & 9.4 & 8.9 & 9.7 \\
\hline Community engagement & 17.1 & 15.8 & 14.7 & 12.7 & 12.9 & 13.2 & 15.6 & 12.4 & 14.3 \\
\hline Exclusion in two or more domains & 11.0 & 11.1 & 9.6 & 10.6 & 9.5 & 8.9 & 8.8 & 8.8 & 9.8 \\
\hline
\end{tabular}

